\title{
Sexual dimorphism and patterns of sexual behavior in Lustrochernes argentinus (Pseudoscorpiones: Chernetidae)
}

\author{
Rocio Palen-Pietri ${ }^{1,2}$, Alejandra Ceballos ${ }^{1}$ and Alfredo V. Peretti ${ }^{1,2}:{ }^{1}$ Universidad Nacional de Córdoba. Facultad de \\ Ciencias Exactas, Físicas y Naturales. Departamento de Diversidad Biológica y Ecología. Cátedra de Diversidad \\ Biológica II. Av. Vélez Sarsfield 299 (C.P: X5000JJC), Córdoba, Argentina. E-mail: rociopalen@gmail.com; ${ }^{2}$ Consejo \\ Nacional de Investigaciones Científicas y Técnicas (CONICET). Instituto de Diversidad y Ecología Animal (IDEA). \\ Laboratorio de Biología Reproductiva y Evolución. Av. Vélez Sarsfield 299 (C.P: X5000JJC), Córdoba, Argentina.
}

\begin{abstract}
Sexual dimorphism between females and males can sometimes be related to particular mating behaviors. In pseudoscorpions, very little is known about the relationship between sexual size dimorphism (SSD) and reproductive behavior. This paper describes sexual dimorphism and the mating behavior patterns of Lustrochernes argentinus (Thorell, 1877), a Neotropical species of Cheliferoidea. We measured different body structures and appendages of 14 individuals of each sex, with the values compared with a T-test. We also analyzed the sexual behavior repertoire occurring during mating between nine couples. We found SSD for several structures: the fixed and movable finger width, and the angle between IV coxae are larger in females, in contrast with the gap between fingers which is bigger in males. The analysis of sexual behavior patterns in this species showed that the reproductive behavioral repertoire is structured in three phases: Phase I (examination), Phase II (spermatophore deposition) and Phase III (sperm transfer) with a mean duration of $2.2 \mathrm{~min}, 5 \mathrm{~min}$, and $7.5 \mathrm{~min}$, respectively. Some structures that showed SSD, and also the composition and duration of different behavioral phases, are different from those of other species of the family Chernetidae. We discuss the results based on current knowledge in pseudoscorpion biology with prospects of further studies studying sexual selection.
\end{abstract}

Keywords: Pseudoscorpions, sexual size dimorphism, courtship, mating behavior

Differences between sexes in morphology, physiology, and behavior are called sexual dimorphism (Fairbairn et al. 2007). One type is sexual size dimorphism (SSD), referring to differences in mean body size between males and females, the evolutionary causes of which are still subject to major controversies (Lovich \& Gibbons 1992).

Many studies of these issues have been carried out in spiders due to their great diversity, wide distribution, and ease of collection, but also because of the great variety of reproductive strategies and patterns displayed before, during and after mating (Choe \& Crespi 2004; Eberhard 2004; Huber 2005; McLean et al. 2018). Recently, these studies have extended to other arachnids that also present an abundance of behavioral patterns, such as scorpions (Peretti 2003, 2010; Peretti \& Carrera 2005; Vrech et al. 2014; Olivero et al. 2015). Studies of sexual selection, sexual dimorphism, mating systems, life history, and sexual pheromones have also been carried out in harvestmen (Nazareth \& Machado 2009; Munguía-Steyer et al. 2012; da Silva Fernandes \& Willemart 2014; Machado et al. 2016), but other orders, such as pseudoscorpions, are still neglected.

Pseudoscorpions are arachnids with an evolutionary history that dates back to the Mid-Devonian period (390 Ma) (Harms \& Dunlop 2017). Their morphology and adaptation to the environment have changed little during this time (Judson 1998, 2000).

Sexual dimorphism in pseudoscorpions is generally restricted to the genital area, although it is also found in other body parts, such as the coxal sacs, coxae, cheliceral galea and tarsal claws (e.g., Chamberlin 1931; Weygoldt 1969; Muchmore 1974; Zeh 1987; Sato 1991; Zeh \& Zeh 2013). Females are generally larger than males (Zeh 1987), but exceptions to this are found within the family Chernetidae (Weygoldt 1969; Harvey 1995), where males of some species may have larger chelae than the females, and some have keels on their chelae, as in Semeiochernes Beier, 1932 and Mirochernes Beier, 1930. There are extremely long pedipalps in Metagoniochernes Vachon, 1939, which are presumably used during courtship or in male-male combat (Chamberlin 1931; Vachon 1939; Weygoldt 1969).

All pseudoscorpions use indirect sperm transfer mediated by a spermatophore placed on the ground, as in other orders of Arachnida, such as Scorpiones, Amblypygi, Uropygi and some Acari (Zeh \& Smith 1985). Pseudoscorpions are ovoviviparous and usually have three postembryonic stages before adulthood (Weygoldt 1969). Only species from the superfamily Cheliferoidea have seminal receptacles, a complex spermatophore, and a mating dance during their courtship (Harvey 1992). These spermatophores exhibit different degrees of complexity and generally consist of a stem and a sperm package. In Cheliferidae and Chernetidae, spermatophores also have a drop of fluid under the sperm package that acts as a trigger mechanism to help sperm enter the female genital atrium (Weygoldt 1966, 1969).

In some pseudoscorpions, the spermatophore is deposited in the absence of the female who locates it, presumably using chemical cues. This behavior is considered to be the ancestral condition within the order (Chamberlin 1931; Beier 1932; Weygoldt 1966, 1969, 1990; Schaller 1979; Thomas \& Zeh 1984; Harvey 1992). In other families, spermatophores are deposited only in the presence of a female (Weygoldt 1966, 1969, 1990), while in derived taxa (Cheliferoidea), spermatophore deposition is preceded by courtship (Weygoldt 1966, 1969, 1990; Boissin 1973; Brach 1978; Thomas \& Zeh 1984; Harvey 1992). These differences in the reproduction of pseudoscorpions could indicate an evolutionary transition from a dissociated model of sperm transfer to an undissociated 

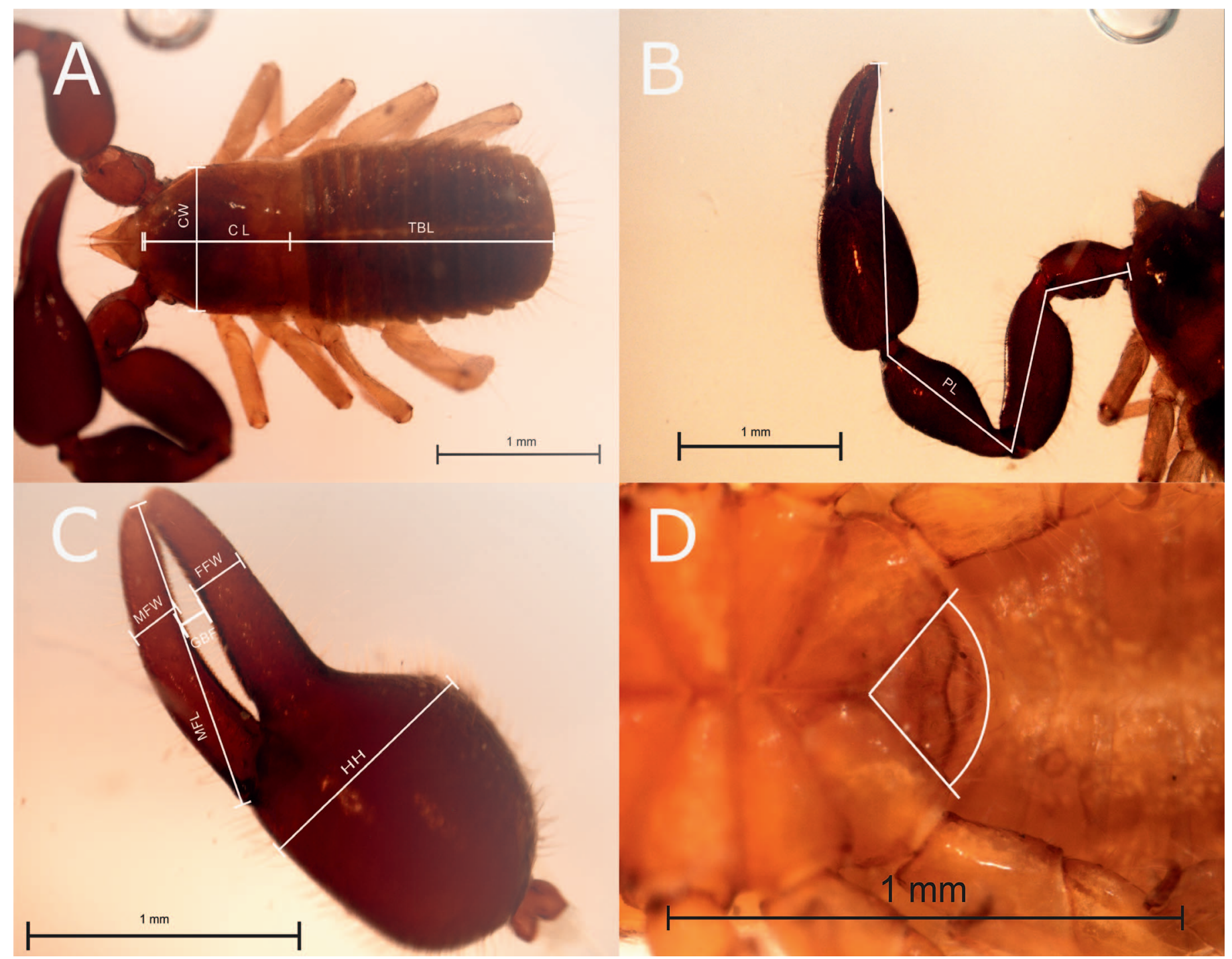

Figure 1.-Measurements of each structure for sexual dimorphism analysis. (All photos are of a male.) A. Total body length (TBL), carapace length (CL) and carapace width (CW); B. Pedipalp length (PL); C. Hand height (HH), fixed and movable finger width (FFW, MFW) and the gap between fingers (GBF); D. Angle between coxae IV.

one (i.e., there is temporary pair formation) (Weygoldt 1966; Harvey 1992).

Studies of the sexual behavior of pseudoscorpions are scarce worldwide, with only a few species studied by Vachon (1939), Weygoldt (1966, 1969), Zeh \& Zeh (1991, 1997), and Andrade \& Gnaspini (2003). Maxchernes iporangae Mahnert \& Andrade, 1998 (Chernetidae), is the only South American species for which we have detailed knowledge of its courtship and mating (Andrade \& Gnaspini 2003).

This paper describes sexual dimorphism and the mating behavior patterns of Lustrochernes argentinus (Thorell, 1877), a Neotropical species of Cheliferoidea, of which there are only preliminary studies of its sexual behavior (Ceballos 2008; Grimaldi et al., unpub. data; Cavigliaso et al., unpub. data). We expect that in the future this knowledge will allow for advances in experimental work in this species in order to explore functional aspects of sexual behavior and sexual size dimorphism.

\section{METHODS}

Specimens of Lustrochernes argentinus were collected in Villa la Merced, Calamuchita Department, Córdoba, Argentina $\left(31.82^{\circ} \mathrm{S}, 64.52^{\circ} \mathrm{W}\right)$ between September 2015 and March 2016. They were taken in the daytime from under the bark of Eucalyptus sp. and were placed individually in Eppendorf tubes. Once in the laboratory, individuals were sexed under a stereomicroscope (Nikon SMZ1500) using genital opercula coloration, the presence of apodemes and the chaetotaxy of the genital region according to Ceballos (2008). Afterward, they were placed individually in plastic containers $(2.5 \times 2.5$ $\mathrm{cm})$ with a piece of the bark from which each was collected. They were moistened and fed with Drosophila melanogaster larvae once a week.

To study the existence of sexual dimorphism, the genital region and various body structures (whole body, pedipalp, chelae, genital operculum, leg IV, among others) (Fig. 1) were photographed from individuals lodged in the CDA (Animal 
Table 1.- Mean value in $\mathrm{mm}$ for each structure in males and females of Lustrochernes argentinus. FBL= Full body length. $*$ Indicates significant difference between males and females as determined by T-test or Mann-Whitney U test (depending on the normality of the data). $\dagger$ T-test, T- value presented; + - Mann-Whitney U Test, Z-value presented.

\begin{tabular}{|c|c|c|c|c|c|c|}
\hline \multirow[b]{2}{*}{ Structure } & \multicolumn{2}{|c|}{ Female $(\mathrm{N}=14)$} & \multicolumn{2}{|c|}{ Male $(\mathrm{N}=14)$} & \multirow[b]{2}{*}{ Statistic } & \multirow[b]{2}{*}{ p-value } \\
\hline & Mean & Structure/FBL & Mean & Structure/FBL & & \\
\hline Full body length & 2.764 & & 2.797 & & & \\
\hline Carapace length & 0.955 & 0.350 & 0.877 & 0.335 & $0.904 \uparrow$ & 0.375 \\
\hline Carapace width & 0.962 & 0.351 & 0.899 & 0.327 & $1.559 \dagger$ & 0.132 \\
\hline Pedipalp length & 4.524 & 1.664 & 4.644 & 1.730 & $-0.610 \dagger$ & 0.548 \\
\hline IV leg length & 2.319 & 0.854 & 2.379 & 0.887 & $-0.623 \dagger$ & 0.539 \\
\hline Chelicera length & 1.745 & 0.640 & 1.673 & 0.622 & $0.611 \dagger$ & 0.547 \\
\hline Chelicera width & 0.606 & 0.646 & 0.565 & 0.612 & $0.559 \ddagger$ & 0.577 \\
\hline Movable finger width & 0.801 & 0.294 & 0.772 & 0.288 & $0.366 \dagger$ & 0.718 \\
\hline Fixed finger length & 0.187 & 0.068 & 0.161 & 0.060 & $2.111 \div$ & $0.035^{*}$ \\
\hline Fixed finger width & 0.222 & 0.081 & 0.173 & 0.064 & $3.856 \dagger$ & $0.001 *$ \\
\hline Gap between fingers & 0.032 & 0.012 & 0.058 & 0.021 & $-4.849+$ & $0.001^{*}$ \\
\hline IV coxae angle & 109.89 & 40.067 & 95.305 & 35.449 & $3.066 \dagger$ & $0.005^{*}$ \\
\hline Hand silhouette & 1.058 & 0.388 & 0.953 & 0.353 & $1.354 \dagger$ & 0.188 \\
\hline
\end{tabular}

Diversity I Department Collection, Facultad de Ciencias Exactas, Físicas y Naturales, Universidad Nacional de Córdoba) which are kept in $80 \%$ ethanol. Also we used individuals collected for the behavioral observation (preserved in $80 \%$ ethanol after their death). Fourteen individuals of each sex were photographed with a camera (Nikon Digital Sight DS-FI1-U2) attached to a stereomicroscope (Nikon SMZ1500). Images were taken over graph paper under different magnifications. These were analyzed using the ImageJ 1.45 (Schneider et al. 2012) photo analysis program. We measured the length and width of the carapace, total body length, chelicera length, left pedipalp and IV leg length, fixed finger length, fixed and movable finger width and the gap between them, the angle between the fourth coxae, all calculated following Chamberlin (1931), and the hand silhouette according to Zeh (1987). Finally, we calculated a proportion index for each structure (X structure/total body length) in each specimen and then calculated the mean value, according to Olivero et al. (2012). A T-test or Mann-Whitney test (depending on the normality of data) was performed to compare the proportion index between males and females, using the program NCSS (๔ Hintze, 2015).

To observe mating behavior, nine random couples were placed in plastic capsules $(2.5 \times 2.5 \mathrm{~cm})$ with a glass lid and a cork sheet at the bottom to simulate tree bark and to allow a better grip and locomotory movements. To be able to identify the male and the female in the videos, we added a tiny dot with non-toxic paint on the dorsum of one of them. The couple was filmed for 30 minutes or until the mating was finished, which was observed with a webcam (Logitech QuickCam pro 9000) attached to a stereomicroscope (Bausch \& Lomb 0.7X-3.0X). Videos were analyzed using JWatcher software (Blumstein et al. 2007) to determine the sexual behavior repertoire occurring during mating. From these patterns, we analyzed common

Table 2.-Description of each behavioral unit observed during L. argentinus mating. For each unit, the phase to which it belongs is indicated: $\mathrm{Ph}$ I (examination), Ph II (spermatophore deposition), Ph III (sperm transfer).

\begin{tabular}{|c|c|c|}
\hline Behavioral unit & Description & Phase \\
\hline Chasing & $\begin{array}{l}\text { Both male and female get closer and attempt to grasp each other while moving to different parts of the } \\
\text { capsule. }\end{array}$ & $\mathrm{Ph} \mathrm{I}$ \\
\hline Touching with chelae & The male touches the female chela, leg I or leg II and on occasions, chelicerae. & $\mathrm{Ph} \mathrm{I}$ \\
\hline Chelae grasping & One of the individuals grasps the other one's chela. & $\mathrm{Ph} \mathrm{I}$ \\
\hline Walking & While gripped by one or both chelae, they change position inside the capsule. & $\mathrm{Ph} \mathrm{I}$ \\
\hline Pedipalps locking & $\begin{array}{l}\text { With the male grasping both female chelae, they approach very closely (while still grasping), resulting } \\
\text { in their chelicerae being close to each other. They retract their pedipalps on both sides of the body } \\
\text { and remain in this position until spermatophore deposition is over. }\end{array}$ & $\mathrm{Ph}$ II \\
\hline Chelicerae rubbing & Both individuals rub their chelicerae with the other without losing grip. & $\mathrm{Ph} \mathrm{II}$ \\
\hline Rubbing with legs & While being grasped, one of the individuals rubs a leg with the partner's leg I & $\mathrm{Ph}$ II \\
\hline Carapace movements & Female performs a slight lateral movement with her carapace. & $\mathrm{Ph}$ II \\
\hline Body lifting & Male begins to raise the posterior part of his opisthosoma, still gripping the female chelae. & $\mathrm{Ph}$ II \\
\hline Spermatophore deposition & $\begin{array}{l}\text { With his opisthosoma raised, the male deposits the spermatophore and shakes his body to get rid of it, } \\
\text { without letting the female go. }\end{array}$ & $\mathrm{Ph}$ II \\
\hline Pedipalp pulling & Once the spermatophore is deposited, there is pedipalp pulling by both individuals. & $\mathrm{Ph}$ III \\
\hline Separation & They lose grip, and the couple separates before the sperm tran & $\mathrm{Ph}$ III \\
\hline Sperm transfer & $\begin{array}{l}\text { Female places herself over the spermatophore and rubs her genital operculum with the substrate to } \\
\text { press the spermatophore and perform the sperm transfer. }\end{array}$ & $\mathrm{Ph}$ III \\
\hline Walk away & Both individuals walk away from each other. & $\mathrm{Ph}$ III \\
\hline
\end{tabular}




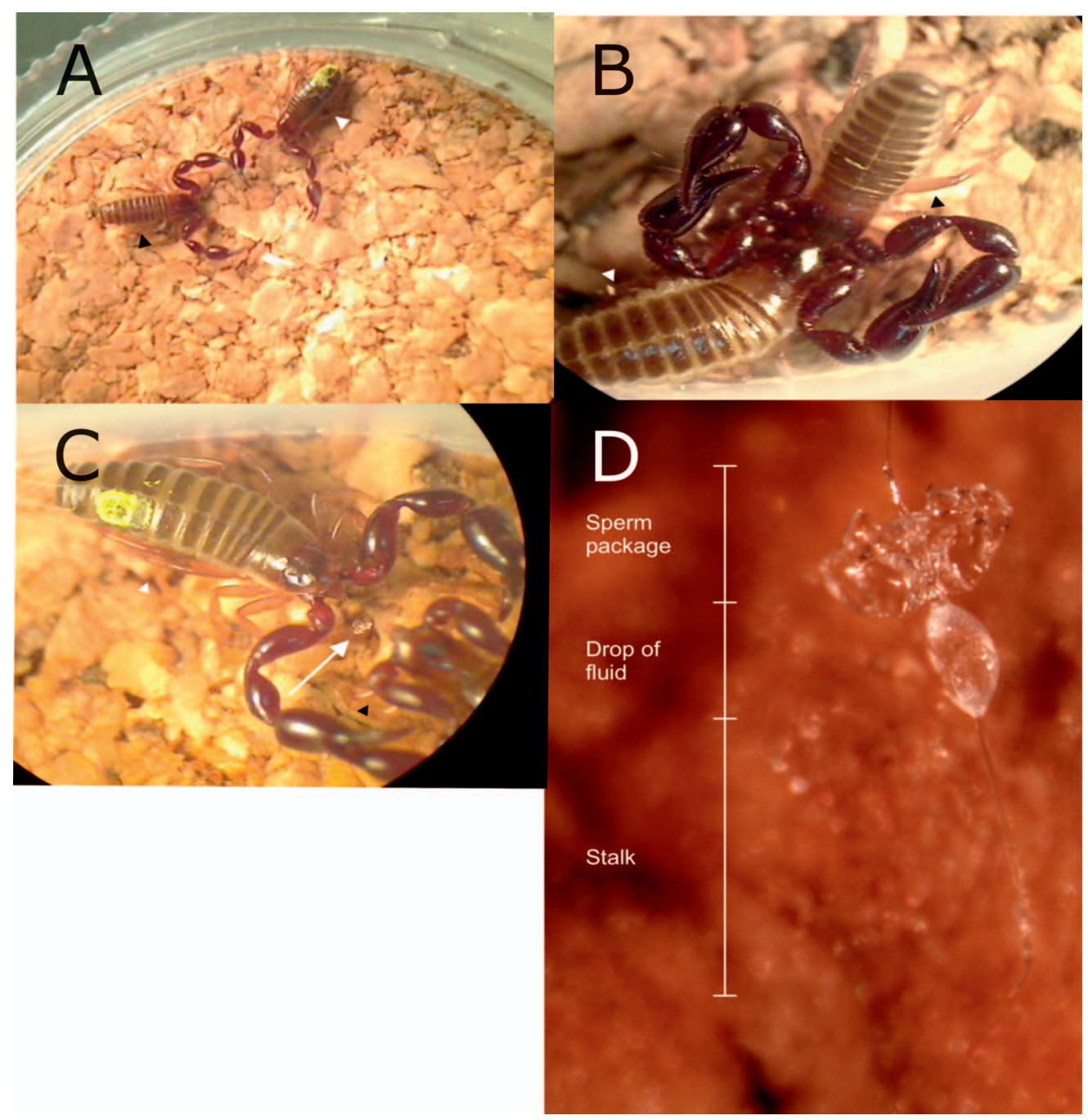

Figure 2.-Phases identified during mating. A. Phase I: examination - the male is grasping one of the female's chelae. B. Phase II: spermatophore deposition - the pedipalps in locking position. C. Phase III: sperm transfer-individuals are performing pedipalp pulling; the white arrow is pointing to the spermatophore between them. D. L. argentinus spermatophore in detail. $\Delta$ Female, $\Delta$ Male

behaviors trying to identify possible phases and then calculating the duration and frequency of characteristic behaviors. The results were summarized in a flow diagram, showing the behavioral units of each phase and their relationships.

\section{RESULTS}

The structures that showed sexual dimorphism were the fixed and movable finger width and the angle between IV coxae, which were larger in females. The gap between the fingers was significantly larger in males (Table 1).

The analysis of sexual behavior patterns showed that the reproductive behavioral repertoire was composed of the behavioral units listed in Table 2. Mating commenced when the male grasped the female's pedipalp and ended when the spermatophore was transferred. Three phases were identified:

Phase I (examination) (Fig. 2A): Chasing and constant chela touching characterized this phase. Generally, the male grasped the female by one chela and, in $20 \%$ of cases, with the other chela he rubbed leg I or II (in 10\%, the chelicerae). This grasping continued, and on some occasions, was also instigated by the female. The mean duration of this phase was $133.4 \pm 115.8 \mathrm{sec}$.

Phase II (spermatophore deposition) (Fig. 2B): This stage was initiated with pedipalp locking, remaining in this position until the finalization of spermatophore deposition. In 10\% of the cases, cheliceral rubbing by both individuals or only by the female was observed. Then, in all 14 cases, the male raised the posterior part of his opisthosoma which indicated that he was depositing the spermatophore on the substrate (Fig. 2D). The deposition of the spermatophore constituted the end of this phase, which had a mean duration of $275.6 \pm 52.2 \mathrm{sec}$ (approximately 5 minutes).

Phase III (sperm transfer) (Fig. 2C). This stage commenced when the pair began to pull each other's pedipalps, moving only a few millimeters. This pulling continued for a few seconds, and then the couple separated, the female approached the spermatophore and rubbed her genital opening over the sperm package and performed sperm transfer, indicating the end of 


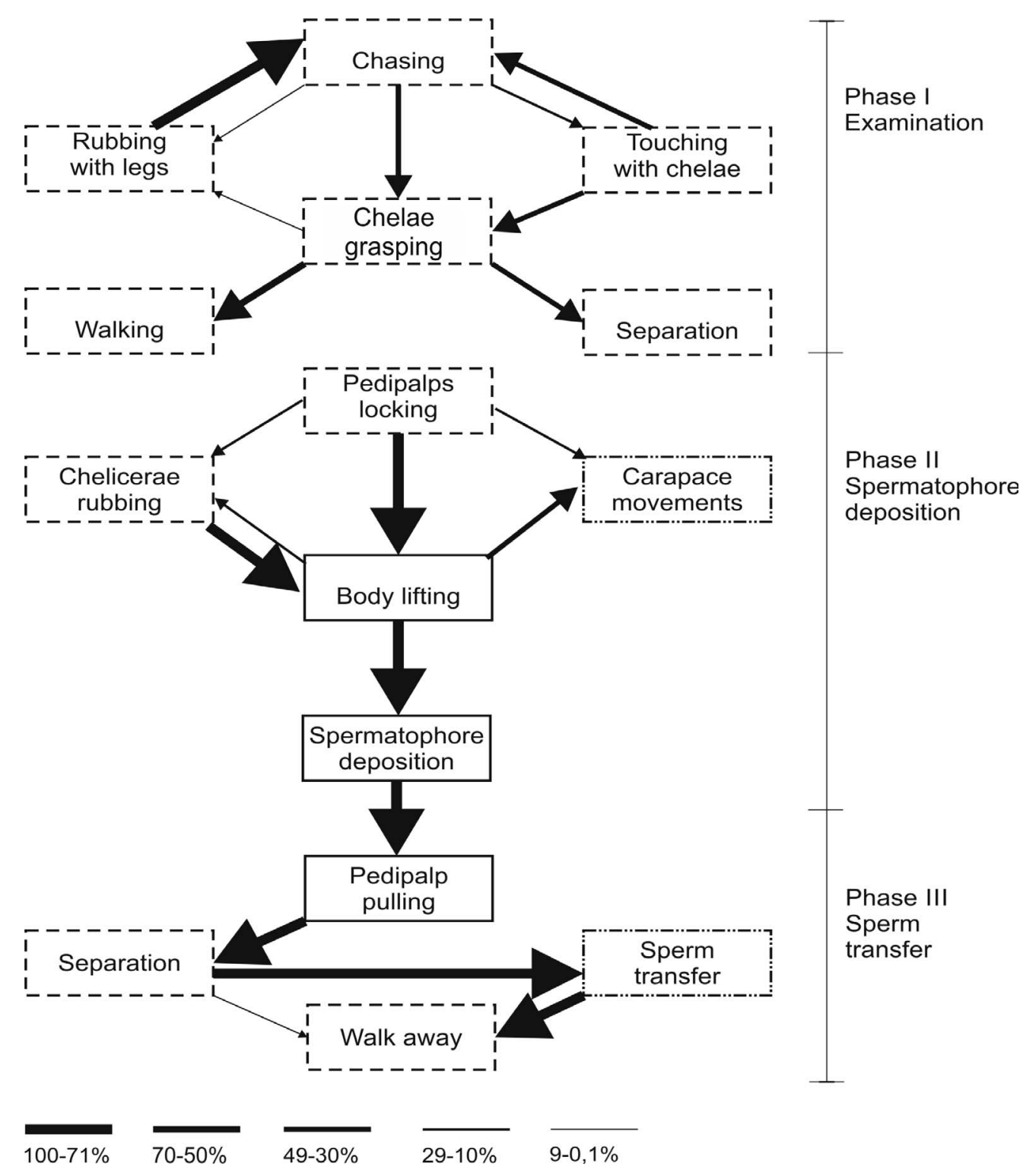

Figure 3.-Flow diagram showing the relationships between the behavioral units. The thickness of the arrows represents the frequency of transition between units. Boxes with continuous lines indicate behavioral units that were performed only by males, dashed lines represent units that were performed by females and mixed lines represent units that were performed by both individuals.

this phase and mating. The mean duration of this phase was $10.1 \pm 6.4 \mathrm{sec}$, the shortest of the three phases.

The mean duration of mating was $418.0 \pm 146.9 \mathrm{sec}$ (approximately $7.5 \mathrm{~min}$ ). All three phases and behavioral units are shown in a flow diagram (Fig. 3).

\section{DISCUSSION}

The chelae of female Lustrochernes argentinus are larger than those of males, as reported for most pseudoscorpions species (Zeh 1987). Some chernetid species, however, such as Dinocheirus arizonensis (Banks, 1901), Barbaraella mainae Harvey, 1995, Cordylochernes scorpioides (Linnaeus, 1758), among others, the male chelal size is $60 \%-150 \%$ larger than in females (Zeh 1987; Harvey 1995; Zeh \& Zeh 2013). The chelal size in L. argentinus is $10 \%$ larger in females than in males.
Despite the larger chelae in females, the gap between the fingers is $40 \%$ wider in males, which could be explained by the male needing to provide a firm grip during mating, with the wider gap allowing better attachment to the female chelae. From a functional perspective of sexually dimorphic traits, similar situations in other arachnids have been observed. For example, in the scorpion Zabius fuscus (Thorell, 1877) males have gaps in the chelal fingers that are larger than those of the females, a feature that facilitates holding and moving together during mating (Peretti 1991, 2000, unpubl. data; Peretti \& Carrera 2005).

In general, almost all chernetid species show common behavior patterns in their courtship. However, there are also small peculiarities that differentiate species from each other. For example, the behavioral phases described for the mating of $L$. argentinus partially match with those described for $M$. 
iporangae by Andrade \& Gnaspini (2003). As expected, we observed similarities in mating in both species (i.e., pedipalp grasping, locomotion and pedipalp moving, among other behavioral units) but there are other behaviors that are restricted to each species, such as the vibration of the forelegs in $M$. iporangae or cheliceral rubbing in L. argentinus.

Duration of the behavioral phases in L. argentinus is significantly different, even compared with other species of the family. In L. argentinus, what we called the "sperm transfer" phase includes the couple's separation and the immediate use by the female of the deposited spermatophore, all with a mean duration of only nine seconds. In contrast, in M. iporangae, where these behaviors are divided into "spermatophore deposition and transfer" and "post-transfer" phases, the latter has a mean duration of 33-80 minutes, during which the male continues to hold the female's pedipalps, and it is not until the end of the phase that the couple separates (Andrade \& Gnaspini 2003).

On the other hand, another interesting difference is observed in Epactiochernes tumidus (Banks, 1895) with a mean mating duration of 15-30 minutes during which a new spermatophore is deposited by the male and transferred to the female every 5-7 minutes (Weygoldt 1966). These variations of duration between species could explain the differences in phase determination time, which is entirely subjective. However, as mentioned, sperm transfer and couple separation in $L$. argentinus occurs in only nine seconds, a rapid transition that would not be considered an exclusive "post-transfer" behavior. The mean duration of mating in L. argentinus is approximately seven minutes, which is considerably less than that of $M$. iporangae of $63.3 \pm 13.9 \mathrm{~min}$, and even compared with other chernetid species, such as Dendrochernes cyrneus (L. Koch, 1873), 120-180 min (Kew 1912), Lamprochernes minor Hoff, 1949, 25-45 min (Levi 1953), and Lasiochernes pilosus (Ellingsen, 1910), with 15-60 min (Weygoldt 1969).

From a sexual selection perspective, female animals were traditionally thought of as passive participants during courtship and mating, but this could be due to a bias toward observing only male behavior in classic studies (Briceño \& Eberhard 2017). Signaling in female arachnids and the effect that it has on the male is an essential feature in the intersexual interactions (Eberhard 2005; Peretti et al. 2006). In this context, the discovery that female L. argentinus actively performs the sperm transfer is a unique feature within pseudoscorpions, since it has not been observed in any other species. Preliminary studies also suggest that females may modulate this behavior and decide whether or not to use the spermatophore depending on the male parasitic burden (Palen-Pietri R. \& A. Ceballos, 2017, unpubl. data). Hence, the female behavior of performing, or not, sperm transfer could respond to cryptic female choice (Eberhard 1996). In any case, as we mentioned, studies regarding mating behavior in pseudoscorpions are still scarce. It would be interesting to expand this line of knowledge in the group to determine if this behavior is observed in other species and what implication it has for sexual selection.

\section{ACKNOWLEDGMENTS}

The authors would like to thank Biol. Javier Poblete Palacios (UNC) for his participation in the early stages of this investigation. We also thank two anonymous reviewers for their useful comments and suggestions on an earlier version of the manuscript and to Dr. Mark Harvey for his valuable help on the content and editing. We are extremely grateful to Joss Heywood for revising the grammar and style in our manuscript. This research was funded by grant Resol 202/16 (PIP 307 20150101834CB) from the "Secretaría de Ciencia y Técnica, Universidad Nacional de Córdoba (SECYT)" and PICT 2069/2014 "Fondo Nacional de Ciencia y Tecnología (FONCYT)" of Argentina, Universidad Nacional de Córdoba, Argentina. Additional funding was provided by CONICET (PIP 2015) and SECYT - UNC.

\section{LITERATURE CITED}

Andrade, R. \& P. Gnaspini. 2003. Mating behavior and spermatophore morphology of the cave pseudoscorpion Maxchernes iporangae (Arachnida: Pseudoscorpiones: Chernetidae). Journal of Insect Behavior 16:37-48.

Beier, M. 1932. Pseudoscorpionidea. II. Subord. Cheliferinea. Das Tierreich 58:1-294.

Blumstein, D.T. \& J.C. Daniel. 2007. Quantifying behavior the JWatcher way. Sinauer Associates Incorporated.

Boissin, L. 1973. Biologie sexuelle du pseudoscorpion Hysterochelifer meridianus (L. Koch) accouplement et description du spermatophore. Bulletin de la Société Zoologique de France 98:521-529.

Brach, V. 1978. Social behavior in the pseudoscorpion Paratemnus elongatus (Banks) (Pseudoscorpionida: Atemnidae). Insectes Sociaux 25:3-11.

Briceño, R.D. \& W.G. Eberhard. 2017. Copulatory dialogues between male and female tse tse flies (Diptera: Muscidae: Glossina pallidipes). Journal of Insect Behavior 30:394-408.

Ceballos, A. 2008. Relevamiento Sistemático y Distribucional de Pseudoscorpiones (Arachnida, Pseudoscorpiones) en las Sierras de Córdoba, Argentina. Tesis Doctoral. Facultad de Ciencias Exactas, Físicas y Naturales. Universidad Nacional de Córdoba, Argentina, Pp. 1-174.

Chamberlin, J.C. 1931. The arachnid order Chelonethida. Stanford University Publications, Biological Science 7:1-284.

Choe, J.C. \& B.J. Crespi (Eds.). 2004. The Evolution of Social Behavior in Insects and Arachnids. Cambridge University Press. Cambridge.

Eberhard, W.G. 1996. Female Control: Sexual Selection by Cryptic Female Choice. Princeton University Press. Princeton.

Eberhard, W.G. 2004. Why study spider sex: Special traits of spiders facilitate studies of sperm competition and cryptic female choice. Journal of Arachnology 32:545-556.

Eberhard, W.G. 2005. Sexually reversed copulatory courtship roles and possible nuptial feeding in the soldier beetle Ditemnus acantholobus (Coleoptera, Cantharidae). Journal of Kansas Entomological Society 79:13-22.

Fairbairn, D.J., W.U. Blanckenhorn \& T. Székely. 2007. Sex, Size and Gender Roles: Evolutionary Studies of Sexual Size Dimorphism. Oxford University Press, Oxford.

Harms, D. \& J.A. Dunlop. 2017. The fossil history of pseudoscorpions (Arachnida: Pseudoscorpiones). Mitteilungen aus dem Museum für Naturkunde in Berlin. Fossil Record 20:215-238

Harvey, M.S. 1992. The phylogeny and classification of the Pseudoscorpionida (Chelicerata: Arachnida). Invertebrate Systematics 6:1373-1435.

Harvey, M.S. 1995. Barbaraella gen. nov. and Cacoxylus Beier (Pseudoscorpionda: Chernetidae), two remarkable sexually dimorphic pseudoscorpions from Australasia. Records of the Western Australian Museum, Supplement. 52:199-208. 
Hintze, J. 2015. NCSS 10 Statistical Software. NCSS, LLC. Kaysville, Utah, USA. Online at http://ncss.com/software/ncss

Huber, B.A. 2005. Sexual selection research on spiders: progress and biases. Biological Reviews 80:363-385.

Judson, M.L.I. 1998. A sternophorid pseudoscorpion (Chelonethi) in Dominican amber, with remarks on the family. Journal of Arachnology 26:419-428.

Judson, M.L.I. 2000. Electrobisium acutum Cockerell, a cheiridiid Pseudoscorpion from Burmese amber, with remarks on the validity of the Cheiridiioidea (Arachnida, Chelonethi). Bulletin-Natural History Museum Geology series 56:79-83.

Lovich, J.E. \& J.W. Gibbons. 1992. A review of techniques for quantifying sexual size dimorphism. Growth Development and Aging 56:269-279.

Kew, H.W. 1912. On the pairing of pseudoscorpions. Proceedings of the Zoological Society of London Volume 1912, part 2:376-390.

Levi, H.W. 1953. Observations on two species of pseudoscorpions. Canadian Entomologist 85:55-62.

Machado, G., B.A. Buzatto, S. García-Hernández \& R. MacíasOrdóñez. 2016. Macroecology of sexual selection: a predictive conceptual framework for large-scale variation in reproductive traits. American Naturalist 188(S1):S8-S27.

McLean, C.J., R.J. Garwood \& C.A. Brassey. 2018. Sexual dimorphism in the Arachnid orders. PeerJ 6:e5751 online at https://doi.org/10.7717/peerj.5751

Muchmore, W.B. 1974. Classification of the genera Hesperochernes and Dinocheirus (Pseudoscorpionida, Chernetidae). Journal of Arachnology 22:25-36.

Munguía-Steyer, R., B.A. Buzatto \& G. Machado. 2012. Male dimorphism of a neotropical arachnid: Harem size, sneaker opportunities, and gonadal investment. Behavior Ecology 23:827-835.

Nazareth, T.M. \& G. Machado. 2009. Reproductive behavior of Chavesincola inexpectabilis (Opiliones, Gonyleptidae) with description of a new and independently evolved case of paternal care in harvestmen. Journal of Arachnology 37:127-134.

Olivero, P.A., C.I. Mattoni \& A.V. Peretti. 2012. Morphometry and geographical variation of Bothriurus bonariensis (Scorpiones: Bothriuridae). Journal of Arachnology 40:113-122.

Olivero, P.A., A. González, C.I. Mattoni \& A.V. Peretti. 2015. Chemical caresses: geographical variation of male sexual signals in a Neotropical scorpion. Behavior 152:1745-1763.

Peretti, A.V. 1991. Comportamiento de apareamiento de Zabius fuscus (Thorell) (Scorpiones, Buthidae). Boletin de la Sociedad de Biologia de Concepcion (Chile) 62:123-146.

Peretti, A.V. 2000. Patrones de resistencia femenina y respuesta del macho durante el apareamiento en escorpiones Bothriuridae y Buthidae: qué hipótesis puede explicarlos mejor? Revista de Etologia 3:25-45.

Peretti, A.V. 2003. Functional morphology of spermatophores and female genitalia in bothriurid scorpions: genital courtship, coercion and other possible mechanisms. Journal of Zoology 261:135-153.

Peretti, A.V. 2010. An ancient indirect sex model: single and mixed patterns in the evolution of scorpion genitalia. Pp. 218-248. In The Evolution of Primary Sexual Characters in Animals. (J. Leonard \& A. Córdoba-Aguilar, ed.) Oxford University Press, Oxford.

Peretti, A.V. \& P. Carrera. 2005. Female control of mating sequences in the mountain scorpion Zabius fuscus: males do not use coercion as a response to unreceptive females. Animal Behavior 69:453-462.

Peretti, A.V., W.G. Eberhard \& R.D. Briceño. 2006. Copulatory dialogue: female spiders sing during copulation to influence male genitalic movements. Animal Behavior 72:413-421.

Sato, H. 1991. Metagoniochernes tomiyamai, a new pseudoscorpion (Chernetidae) from the Ogasawara Islands, Japan. Bulletin of the Biogeographical Society of Japan 46:97-101.

Schaller, F. 1979. Significance of sperm transfer and formation of spermatophores. Pp. 587-608. In Arthropod Phylogeny. (AP Gupta, ed.). Van Nostrand Reinhold Company, New York.

Schneider, C.A., W.S. Rasband \& K.W. Eliceiri. 2012. NIH Image to ImageJ: 25 years of image analysis. Nature Methods 9:671-675.

da Silva Fernandes, N. \& R.H. Willemart. 2014. Neotropical harvestmen (Arachnida, Opiliones) use sexually dimorphic glands to spread chemicals in the environment. Comptes Rendus Biologies 337:269-275.

Thomas, R.H. \& D.W. Zeh. 1984. Sperm transfer and utilization strategies in arachnids: ecological and morphological constraints. Pp. 179-211. In Sperm Competition and the Evolution of Animal Mating Systems. Academic Press, Florida.

Vachon, M. 1939. Remarques sur la sous-famille des Goniochernetinae Beier a propos de la description d'un nouveau genre et d'une nouvelle espece de Pseudoscorpions (Arachnides): Metagoniochernes picardi. Bulletin du Muséum d'histoire naturelle (2) 11:123-128.

Vrech, D.E., P.A. Olivero, C.I. Mattoni \& A.V. Peretti. 2014. Testes mass, but not sperm length, increases with higher levels of polyandry in an ancient sex model. PloS One 9(4):e94135. doi: 10.1371/journal.pone.0094135.

Weygoldt, P. 1966. Mating behavior and spermatophore morphology in the pseudoscorpion Dinocheirus tumidus Banks (Cheliferinea, Chernetidae). Biological Bulletin 130:462-467.

Weygoldt, P. 1969. The Biology of Pseudoscorpions. Harvard University Press. Cambridge MA.

Weygoldt, P. 1990. Arthropoda-Chelicerata: sperm transfer. Pp. $77-$ 119. In Reproductive Biology of Invertebrates. Oxford and $\mathrm{IBH}$ Publishing Co., New Delhi. Vol. 4 (B).

Zeh, D.W. 1987. Aggression, density, and sexual dimorphism in chernetid pseudoscorpions (Arachnida: Pseudoscorpionida). Evolution 41:1072-1087.

Zeh, D.W. \& R.L. Smith. 1985. Paternal investment by terrestrial arthropods. American Zoology 25:785-805.

Zeh, D.W. \& J.A. Zeh. 1991. Dispersal-generated sexual selection in a beetle-riding pseudoscorpion. Behavioral Ecology and Sociobiology 30:135-142.

Zeh, D.W. \& J.A. Zeh. 1997. Sex via the substrate: Mating systems and sexual selection in Pseudoscorpions. Pp. 329-339. In The Evolution of Mating Systems in Insecta and Arachnida. Cambridge University Press, Cambridge.

Zeh, J.A. \& D.W. Zeh. 2013. On the threshold of dispersal: hitchhiking on a giant fly favours exaggerated male traits in a male-dimorphic pseudoscorpion. Biological Journal of the Linnean Society 108:509-520.

Manuscript received 4 May 2018, revised 15 May 2019. 